\title{
Comparative Analysis of the Adsorption Kinetics of the Methylene Blue Dye on Graphene Aerogel and Activated Coconut Carbon
}

\author{
E.S. Mkrtchyan*, E.A. Neskoromnaya, I.V. Burakova, O.A. Ananyeva, N.A. Revyakina, \\ A.V. Babkin, T.S. Kuznetsova, D.A. Kurnosov, A.E. Burakov \\ Tambov State Technical University, 106 Sovetskaya, 392000, Tambov, Russia \\ * Corresponding author. Tel.: +7 95312165 76.E-mail: elina.mkrtchyan@yandex.ru
}

\begin{abstract}
The comparative adsorption capacity of graphene aerogel and activated coconut carbon in the process of removing the main cationic synthetic dye, methylene blue (MB), from aqueous solutions with an initial concentration of $150 \mathrm{mg} / \mathrm{l}$ was investigated. The characteristics of the new material have been determined using scanning electron microscopy, thermogravimetry, and Raman spectroscopy. The values of the adsorption capacity of graphene aerogel $-420 \mathrm{mg} / \mathrm{g}$ and activated carbon - $205 \mathrm{mg} / \mathrm{g}$ were established. The saturation time in the presence of graphene aerogel was 7 min. The experimental data were processed using kinetic models - pseudo-first and pseudo-second order, Elovich and intraparticle diffusion. According to the results obtained, graphene aerogel is a promising sorption material in the extraction of molecular organic pollutants, namely, synthetic dyes, demonstrating a high efficiency of the target pollutant removal.
\end{abstract}

Keywords

Graphene aerogel; adsorption; activated carbon; organic pollutants; methylene blue; dyes, kinetics.

(C) E.S. Mkrtchyan, E.A. Neskoromnaya, I.V. Burakova, O.A. Ananyeva, N.A. Revyakina, A.V. Babkin, T.S. Kuznetsova, D.A. Kurnosov, A.E. Burakov, 2020

\section{Introduction}

Currently, the issue of purifying waste water resources from toxic pollutants, such as organic dyes is especially acute [1-3].

One of the most common organic dyes is methylene blue (MB) with the chemical formula $\mathrm{C}_{16} \mathrm{H}_{18} \mathrm{ClN}_{3} \mathrm{~S}$, which belongs to the group of quinine imine dyes containing the phenothiazine ring. In aqueous solutions, $\mathrm{MB}$ is in the form of a cation with aligned bonds and has an affinity for materials of an amphoteric nature; in dry form, it is dark green crystals with a bronze luster. MB is readily soluble in hot water and alcohol. This dye is widely used in the light industry for dyeing fabrics, in analytical chemistry for the detection of chlorates, perchlorates, mercury, tin, titanium, in medicine - as an antiseptic for the treatment of infections of the oral cavity and urinary tract, as well as an antidote for cyanide poisoning, carbon monoxide gas and hydrogen sulfide. Due to the high intensity of staining of living tissue, MB is used as a dye in microscopy [4].
MB has a complex structure, extremely stable chemical properties and does not undergo natural decomposition, which leads to the destruction of the ecosystem polluted by it: it hinders the penetration of light and oxygen into the aquatic environment, hinders the natural growth of animals and plants, and causes disturbances in the vital activity of microorganism $\mathrm{MB}$ [5-7]. On contact with the skin, it causes irritation and burning sensations [8]. If a significant amount of $\mathrm{MB}$ enters the human body, it can lead to irreversible damage to the eyes or nausea, vomiting, serious damage to the liver and the digestive system, a burning sensation in the mucous tissues, and psychological disorders after oral taking [5].

Thus, the problem of purifying waste and domestic water from organic dyes, in particular, $\mathrm{MB}$, is relevant and justified. There are many ways to implement the processes of purification of aqueous solution from organic dyes, such as reverse osmosis, electrochemical purification, distillation and sorption. Each of these methods has advantages and disadvantages. Reverse osmosis has a high degree of purification, but it is 
ineffective due to the high costs of maintaining increased pressure. Distillation is also very efficient, but is a very time consuming and energy consuming process. Electrochemical cleaning provides high quality, but requires significant energy consumption [9]. Thus, among all the above methods, adsorption stands out. The advantages of this method are the ability to control the degree of purification of an aqueous solution from contaminating components, as well as the absence of the risk of releasing a side pollutant, often very toxic, which together makes it easy to implement and automate the process of purifying the aquatic environment.

As a rule, the so-called traditional sorbents, such as activated carbon (AC), zeolites, and various polymers are used as sorption materials. The authors in [10] presented the data on the magnitude of adsorption of the MB dye by natural zeolites from Egyptian kaolin. The maximum sorption capacity was $21.41 \mathrm{mg} / \mathrm{g}$ at a temperature of $25^{\circ} \mathrm{C}$, an initial MB concentration of $10 \mathrm{mg} / \mathrm{l}$, a sample volume of $25 \mathrm{ml}$, a sample weight of $0.1 \mathrm{~g}, \mathrm{pH}=7$ for a period of 120 minutes.

In [11], a magnetic polymer functionalized with fullerenes was used as a sorbent. The maximum sorption capacity in terms of $\mathrm{MB}$ at $\mathrm{pH}=10$, a sample weight of $0.02 \mathrm{~g}$, a sample volume of $50 \mathrm{ml}$, and an initial MB concentration of $20 \mathrm{mg} / 1$ was $41.5 \mathrm{mg} / \mathrm{g}$ in a time equal to 30 minutes.

In [12] a monomer of 3,5-diaminobenzoic acid in the presence of $\mathrm{H}_{2} \mathrm{O}_{2}$ (hydrogen peroxide) using oxidative polymerization was obtained. Its calculated adsorption capacity in terms of MB was $61.1 \mathrm{mg} / \mathrm{g}$ at a temperature of $25^{\circ} \mathrm{C}$, a sample weight of $0.03 \mathrm{~g}$, an $\mathrm{MB}$ concentration of $50 \mathrm{mg} / \mathrm{l}$ and a sample volume of $50 \mathrm{ml}$, and the process time was 120 minutes.

In [13] the synthesis of a new polymer from $\beta$-cyclodestrin was described; its sorption capacity for MB was $292.8 \mathrm{mg} / \mathrm{g}$, at a temperature of $25{ }^{\circ} \mathrm{C}$, a sample weight of $0.01 \mathrm{~g}$, and an $\mathrm{MB}$ concentration of $300 \mathrm{mg} / \mathrm{l}$, in 300 minutes.

The sorption capacity of the bifunctional $\mathrm{Zn}$ (II) coordination polymer was studied in [14]. It was $239.57 \mathrm{mg} / \mathrm{g}$ at optimal $\mathrm{pH}=10$, temperature $20{ }^{\circ} \mathrm{C}$, MB concentration $100 \mathrm{mg} / \mathrm{l}$, sample volume $20 \mathrm{ml}$, adsorbent amount $1.5 \mathrm{~g} / \mathrm{l}$, in 60 minutes.

However, the sorption capacity of these materials does not fully meet modern production needs. One of the main ways to improve the sorption characteristics of a material is to modify its surface with substances of various chemical nature. In [15], a magnetic zeolite/nickel ferrite nanocomposite was synthesized and its surface was modified with sodium alginate.
The highest adsorption capacity of $54.05 \mathrm{mg} / \mathrm{g}$ was obtained at $\mathrm{pH}=5$, initial $\mathrm{MB}$ concentration of $10 \mathrm{mg} / \mathrm{l}$, sample weight $0.03 \mathrm{~g}$, sample volume $25 \mathrm{ml}$, temperature $25^{\circ} \mathrm{C}$, in 120 minutes.

Recently, bio char based on plant components with activating additives has been studied. In [6], activated carbon (AC), prepared from macadamia nut shells using activating agents $\mathrm{H}_{2} \mathrm{SO}_{4}$ and $\mathrm{K}_{2} \mathrm{CO}_{3}$, acts as a sorption material. The sorption capacity of $\mathrm{AC}$ with $\mathrm{H}_{2} \mathrm{SO}_{4}$ was $250.22 \mathrm{mg} / \mathrm{g}$ in 60 minutes at an adsorbent dosage equal to $1 \mathrm{~g} / \mathrm{l}$; $\mathrm{AC}$ modified with $\mathrm{K}_{2} \mathrm{CO}_{3}$ was $261.52 \mathrm{mg} / \mathrm{l}$ in 45 minutes at an adsorbent dosage of $0.5 \mathrm{~g} / \mathrm{l}$ and an MB concentration of $70 \mathrm{mg} / \mathrm{l}$ in both cases.

In [8], magnetic nanocomposites of bio char from wakame algae were synthesized for the first time. Samples of magnetic bio char were obtained by impregnation of nickel onto coal treated by means of one-stage carbonization with an activating agent $\mathrm{KOH}$ at $800{ }^{\circ} \mathrm{C}$. The maximum sorption capacity for MB was $479.49 \mathrm{gm} / \mathrm{g}$ at a temperature of $25^{\circ} \mathrm{C}$, the weight of the sample was $0.05 \mathrm{~g}$, the initial concentration of $\mathrm{MB}$ was $350 \mathrm{mg} / 1$, and the process time was 2 hours.

In [16] a highly efficient porous adsorbent from bio char obtained by thermal pyrolysis of seaweed was investigated. A large surface area made it possible to achieve an adsorption capacity for $\mathrm{MB}$ equal to $375.2 \mathrm{mg} / \mathrm{g}$ under the following experimental conditions: temperature $30^{\circ} \mathrm{C}$, sample weight $0.2 \mathrm{~g}$, initial $\mathrm{MB}$ concentration $400 \mathrm{mg} / \mathrm{l}$, adsorption time 7 hours.

The authors of [17] indicated the sorption capacity of multilayer carbon nanotubes with carboxyl functional groups (MWCNT-COOH) integrated into granules of calcium alginate (CA-MWCNT-COOH), which is $1189 \mathrm{mg} / \mathrm{g}$. Experimental studies were carried out at room temperature of $(22 \pm 0.5)^{\circ} \mathrm{C}, \quad \mathrm{MB}$ concentration of $1000 \mathrm{mg} / \mathrm{l}$, a sorbent weight of $15 \mathrm{mg}$, and a solution volume of $40 \mathrm{ml}$.

In [18], a composite adsorbent based on microgranules of carboxymethyl cellulose containing carboxylated graphene oxide (GO) (CMC / GOCOOH) was prepared. The maximum sorption capacity according to $\mathrm{MB}$ was $129.8 \mathrm{mg} / \mathrm{g}$ in 10 minutes at a temperature of $25^{\circ} \mathrm{C}, \mathrm{pH}=10$, a sorbent weight of $0.05 \mathrm{~g}$, a concentration of $200 \mathrm{mg} / \mathrm{l}$, and a solution volume of $50 \mathrm{ml}$. In [7], a porous aerogel composite of graphene oxide and alkaline lignin (GO-AL aerogel) was studied, the maximum sorption capacity for MB of which was $1185.98 \mathrm{mg} / \mathrm{g}$ at $30^{\circ} \mathrm{C}$, at $\mathrm{pH}=7$ and a solution concentration of $0.2 \mathrm{~g} / \mathrm{l}$ in 175 minutes. 
When synthesizing a new sorption material, in addition to its low cost and ability to regenerate, one of the main parameters is its high adsorption capacity after a short period of time. The above sorption materials do not meet these requirements.

The aim of this paper is to study the kinetic parameters of the process of removing the MB dye from aqueous solutions by synthesized graphene aerogel in comparison with a traditional sorption material - coconut AC.

\section{Materials and methods}

\section{Materials}

\section{$R G O$-Aerogel}

It is known that the technology for producing aerogels includes the following main stages: the formation of a gel, its aging, removal of the solvent from the material (drying) [19-21]. In this work, an aerogel based on reduced graphene oxide was obtained. For this, at the first stage, the aqueous dispersion of exhaust gas was subjected to preliminary ultrasonic treatment to reduce the size of agglomerates and reduce the viscosity.

The next stage consisted in the chemical reduction of graphene oxide using ascorbic acid. The choice of this reagent is primarily due to its environmental friendliness, as well as a high degree of recovery, which is confirmed by a sufficient number of scientific works in this area [22-25]. Ascorbic acid was dissolved in water and then added to the prepared aqueous dispersion of GO. The reaction mixture was transferred to a water bath and kept at reflux temperature $\left(100^{\circ} \mathrm{C}\right)$ for 2 hours. After this time, the material was cooled, filtered and washed until the filtrate was neutral. Then, in the resulting hydrogel, water was replaced by isopropyl alcohol, and an alcogel was obtained as an intermediate material.

The final stage, drying, involved supercritical treatment in isopropyl alcohol. It is known that alcohols are the best solvents for such processes, because the point of their transition to the state of supercritical fluid (SCF) is much lower than for water [26]. Isopropyl alcohol was used in the work, the transition of which to SCF occurs at a temperature of $235.3{ }^{\circ} \mathrm{C}$ and $47.6 \mathrm{~atm}$. The resulting alcohol was transferred to an autoclave (high-pressure reactor Nano-Mag Technologles Pvt. Ltd.), the required amount of isopropyl alcohol was poured in, thermostated and kept under these conditions for 6 hours. Next, the reaction space was purged with argon for 30 minutes, cooled, and the finished aerogel was discharged.

\section{Coconut $A C$}

As a reference material, AQUACARB coconutbased activated carbon with a surface area of 1150 $1350 \mathrm{~m}^{2} / \mathrm{g}$ was used (Chemviron Carbon, Belgium).

Dye

The authors of the article used methylene blue dye (analytical grade) (JSC "LenReaktiv", St. Petersburg) as a model pollutant.

\section{Carrying out the adsorption process}

To determine the adsorption capacity of graphene aerogel and coconut $\mathrm{AC}, 30 \mathrm{ml}$ of an $\mathrm{MB}$ solution with an initial concentration of $150 \mathrm{mg} / \mathrm{l}$ was poured into $50 \mathrm{ml}$ Eppendorf tubes, then $0.01 \mathrm{~g}$ of sorbent was added. The test tubes with the test solution and the sorbent weighed were placed into a Multi Bio RS-24 programmable multi-rotator (Biosan, Riga, Latvia), and were continuously stirred at a frequency of $100 \mathrm{rpm}$ at room temperature for $t_{\mathrm{RGO}}=5,10,15,30,60 \mathrm{~min}$ for graphene aerogel, and $t_{\mathrm{AC}}=10,20,40,60 \mathrm{~min}$ for AC. Then the sorbent was separated from the solution using filter paper. Next, the optical density of the filtered $\mathrm{MB}$ solution was measured on a PE-5400VI spectrophotometer (OOO EKROSKHIM, St. Petersburg, Russia) at a wavelength of $\lambda=472 \mathrm{~nm}$.

\section{Results and discussion}

\section{Material}

The surface structure of the sorbent was studied using a MERLIN scanning electron microscope (SEM) (Carl Zeiss, Jena, Germany).

Fig. 1 shows an image of the microstructure of the surface of a graphene aerogel. Analyzing the data obtained, it can be seen that the material has a highly porous structure and consists of graphene flakes.

To identify the ordering of the graphene structure, a study of the material was carried out using Raman spectrometry (DXR ${ }^{\mathrm{TM}}$ Raman microscope (Thermo Scientific Instruments Group, Waltham, USA)). The spectrum of graphene aerogel (Fig. 2) shows two pronounced peaks characteristic of carbon materials: peak D $\left(\sim 1330 \mathrm{~cm}^{-1}\right)$ and peak $\mathrm{G}\left(\sim 1600 \mathrm{~cm}^{-1}\right)$. The intensity of peak $D$ is higher, which indicates a disordered structure of the material, as well as the presence of a large number of defects.

The thermal stability of the sorbent was determined using a NETZSCH STA 449 F3 Jupiter ${ }^{\circledR}$ synchronous thermal analyzer (NETZSCHFeinmahltechnik GmbH, Selb, Germany), which allows 


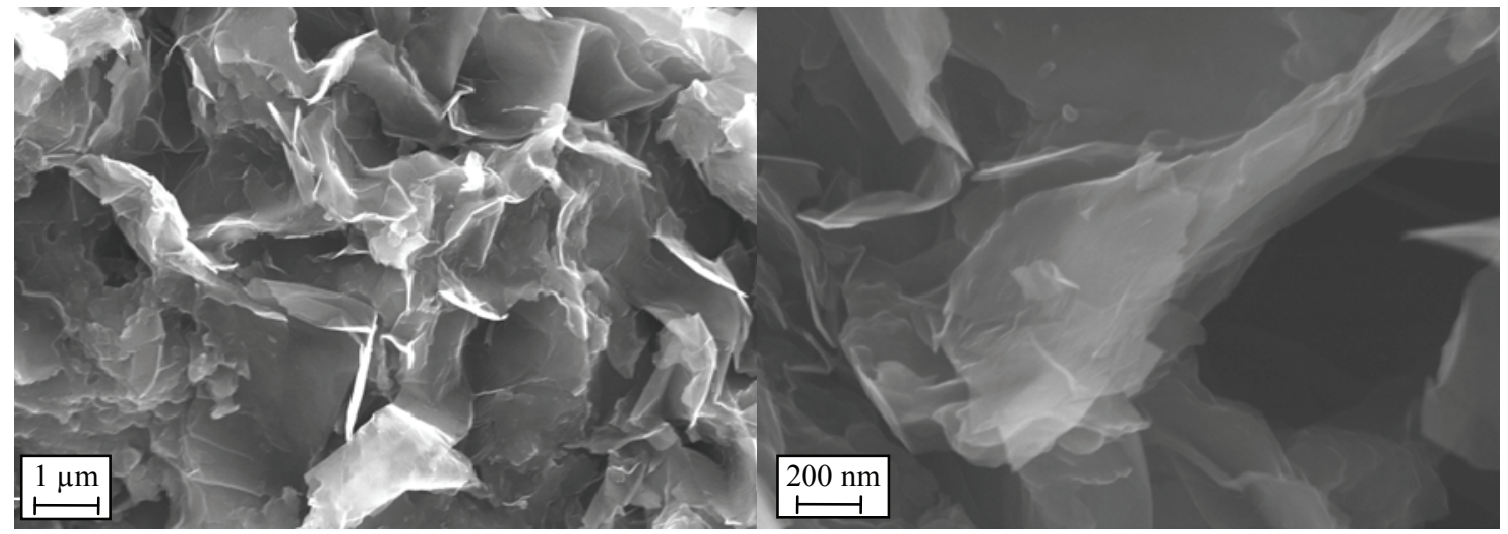

Fig. 1. SEM-images of the surface of a graphene aerogel

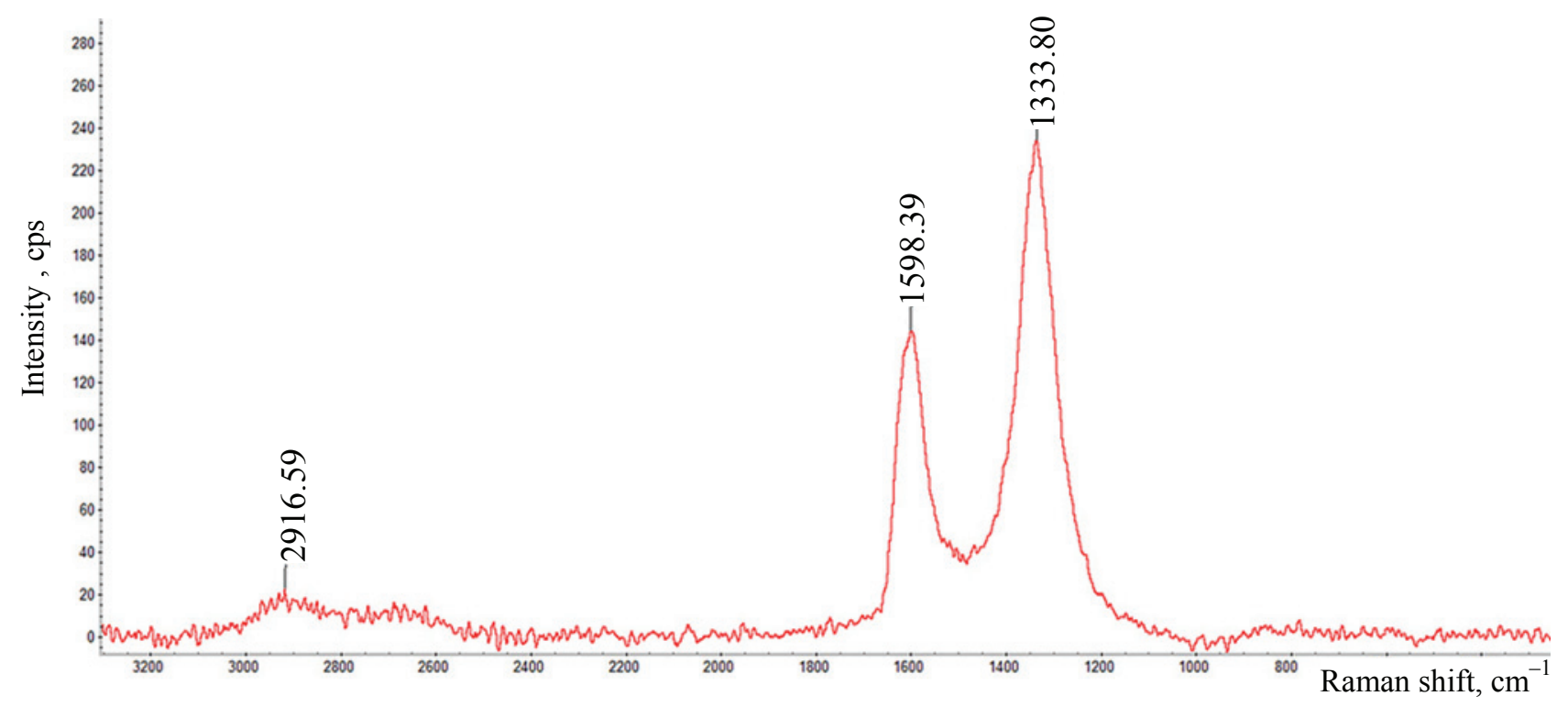

Fig. 2. Raman spectrum of graphene aerogel

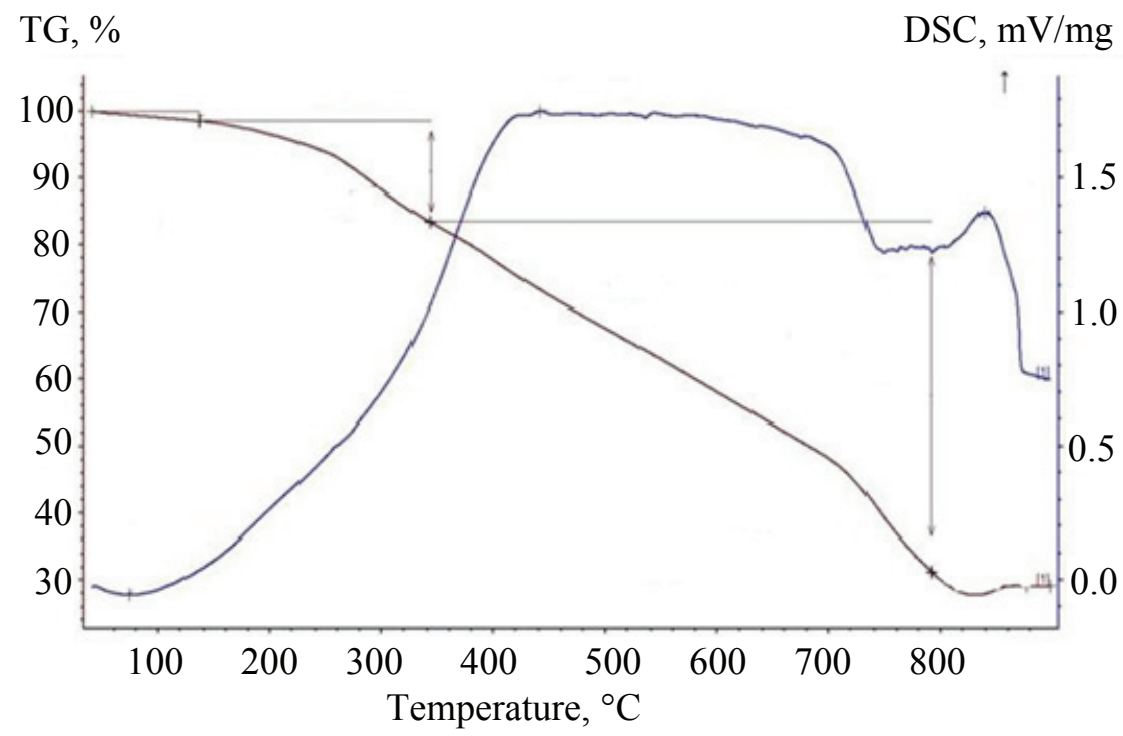

Fig. 3. TG and DSC curves of graphene aerogel 
measuring the mass change (TG) and calorimetric effects (DSC) in the sample. Studies of the material (Fig. 3) showed that the destruction of the ordered carbon masses of the sorbent occurs at $400{ }^{\circ} \mathrm{C}$, while an exothermic peak is observed at $839^{\circ} \mathrm{C}$, at which a loss of $70 \%$ of the mass occurs.

\section{Kinetic research}

The obtained experimental values of optical density were used to calculate the final concentrations of the test solution using the calibration equation.
The Gibbs equation was used to determine the adsorption value:

$$
Q_{e}=\frac{V\left(C_{0}-C\right)}{m},
$$

$Q_{e}$ is Gibbs's adsorption, $\mathrm{mg} / \mathrm{g} ; V$ is system volume, $\mathrm{ml} ; C_{0}$ is adsorbate initial concentration, $\mathrm{mg} / \mathrm{l}$; $C$ is adsorbate concentration in a volume, $\mathrm{mg} / \mathrm{l}$; $m$ is sorbent weight, $\mathrm{g}$.

The results of kinetic studies in a static mode are shown in Fig. 4.

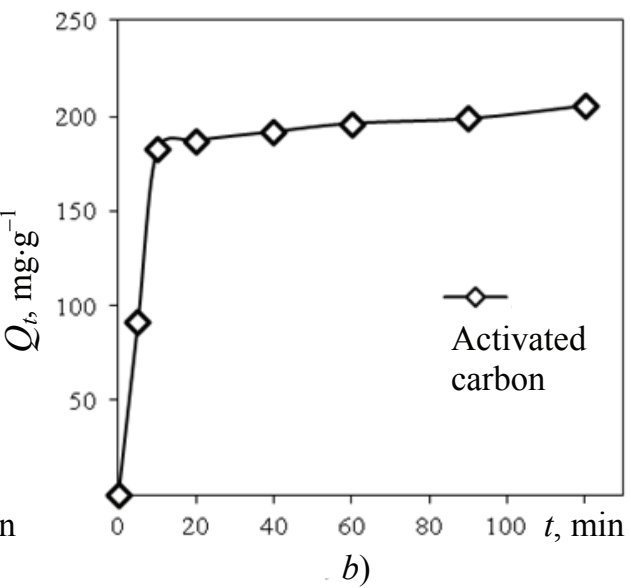

Fig. 4. Kinetic dependences of the adsorption of the MB dye on graphene aerogel (a) and coconut AC (b)

Kinetic parameters of MB adsorption

Table 1

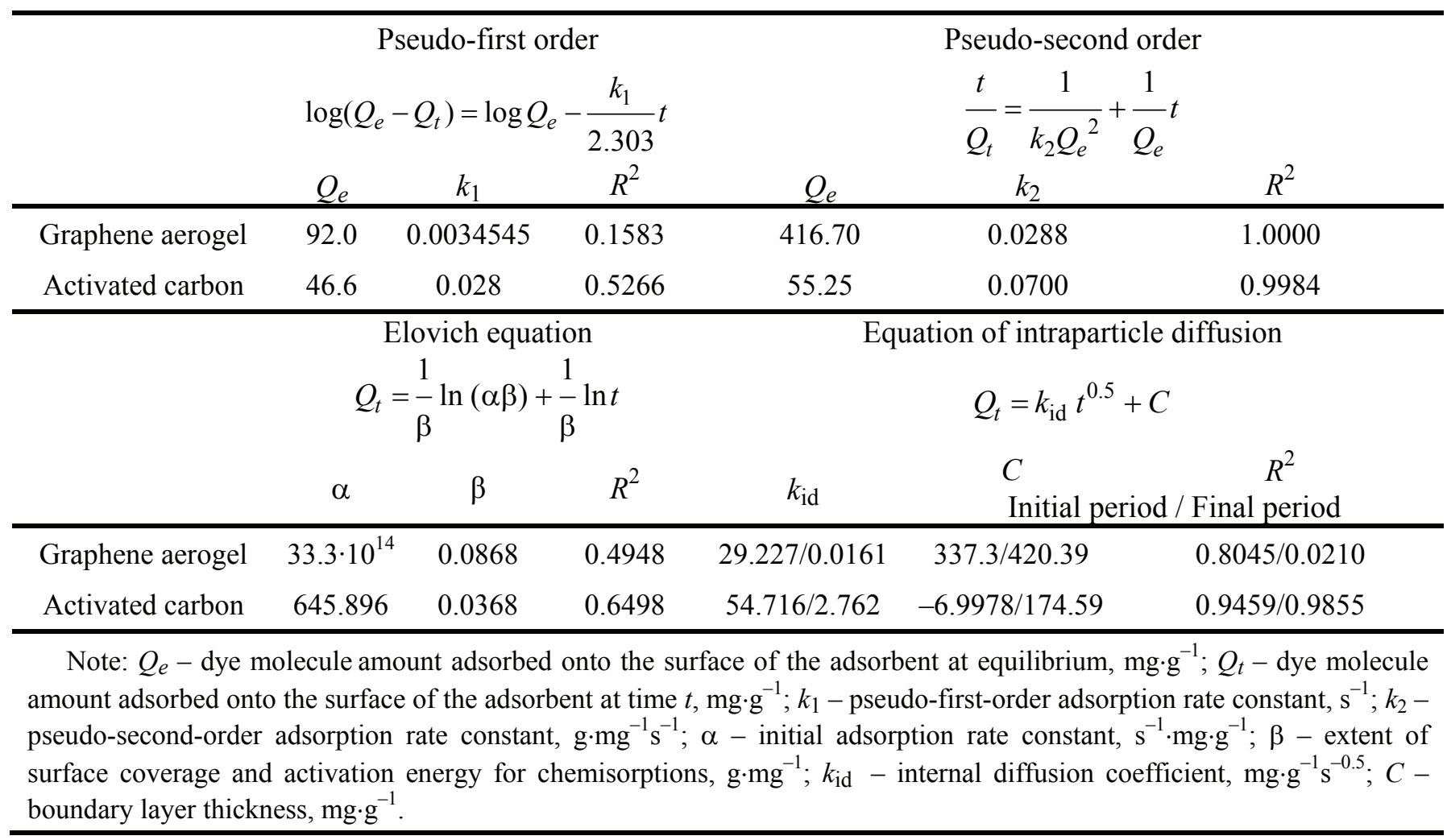


It can be seen that the graphene aerogel reaches its maximum adsorption capacity $(420 \mathrm{mg} / \mathrm{g})$ after $7 \mathrm{~min}$. In turn, coconut $\mathrm{AC}$ actively adsorbs the $\mathrm{MB}$ dye during the first $20 \mathrm{~min}$, then the absorption process slows down significantly. It should be noted that the efficiency of dye removal with coconut AC is two times lower than that of the graphene aerogel obtained by the authors.

To describe the sorption process, namely, the mechanics involved in the transfer of the sorbate to the surface and into the structure of the sorbents, the obtained experimental data were processed by equations of the known kinetic models (pseudo-first and pseudo-second order, the Elovich and intraparticle diffusion) (Table 1) [27].

As a result of processing the experimental data using the indicated kinetic models, it was shown that the mechanism of the sorption process is well described using pseudo-second order equations and intraparticle diffusion in both cases (Fig. $5 a-d$ ).

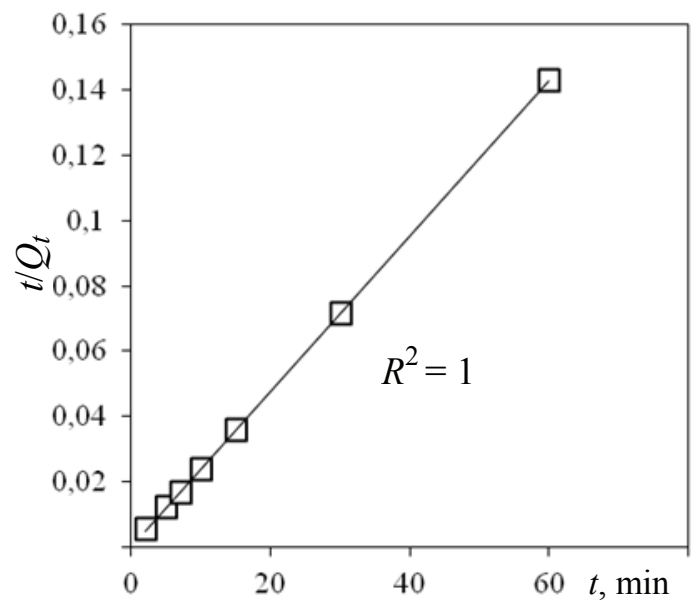

a)

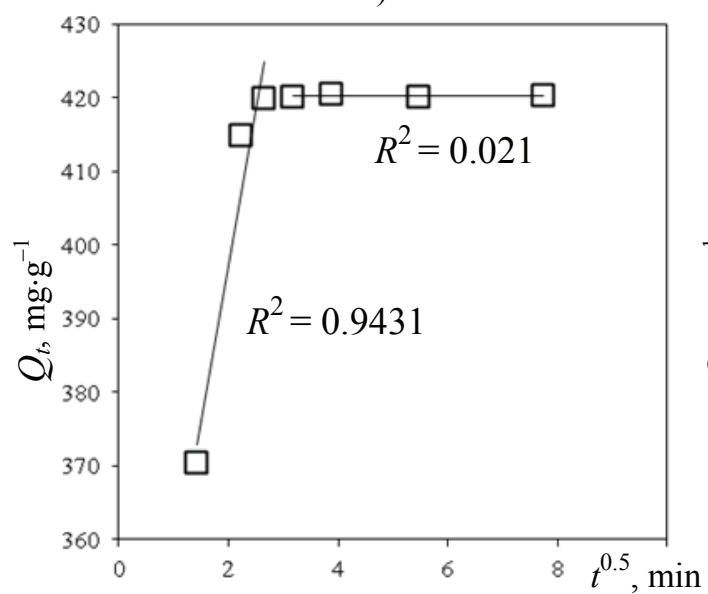

c)
The pseudo-second order model has high correlation coefficients $R^{2}$ (for graphene aerogel, $R^{2}=1$; for $\mathrm{AC}, R^{2}=0.9984$ ). Accordingly, we can conclude that the reaction between the adsorbate and the functional groups of the sorbent proceeds strictly stoichiometrically (one molecule occupies one position on the sorbent), i.e. a chemical interaction occurs between the dye molecules and the functional groups of the sorbent.

According to the internal diffusion model (Fig. $5 c, d$ ), both sorbents are characterized by the separation of the kinetic curve into two sections. This fact indicates that the process has a mixeddiffusion nature. Kinetic data with good correlation are described at the first stage of dye absorption using both sorbents. In turn, when using coconut $\mathrm{AC}$ in Fig. $5 d$, the experimental data are well described by the model of internal diffusion in two regions of the kinetic dependence. In this case, it is typical for AC that the

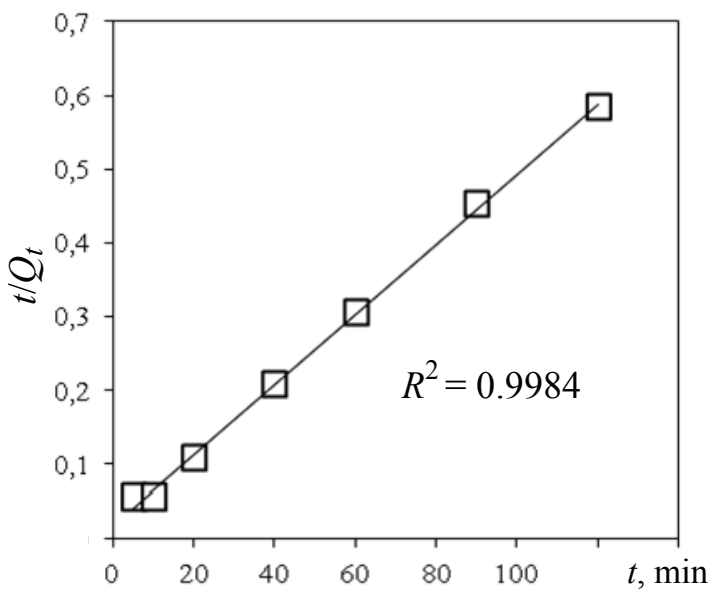

b)

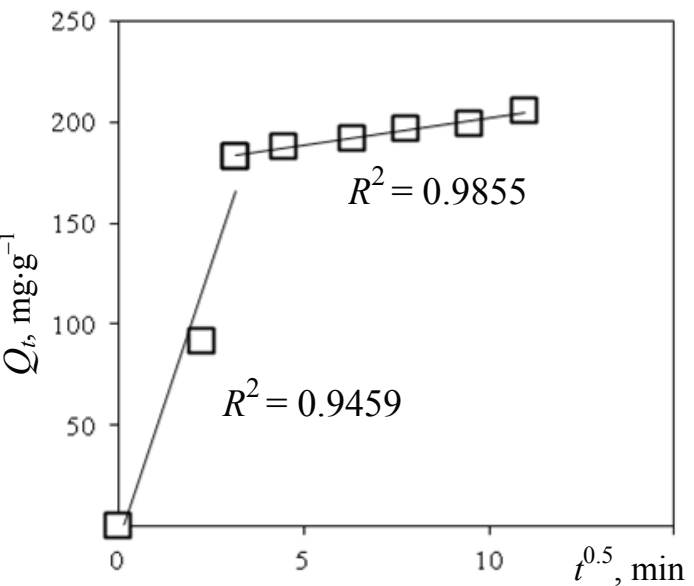

d)

Fig. 5. Results of mathematical processing of experimental kinetic dependences by pseudo-second order models: $a$ - graphene aerogel; $b$ - coconut AC; intraparticle difussion: $c$ - graphene aerogel; $d$-activated carbon 
linear dependence comes out of the origin. This fact suggests that in the initial period of time, the process of sorption on AC is limited mainly by internal diffusion.

For each of the stages, the adsorption rate constants kid were determined, as well as the thickness of the boundary layer $\mathrm{C}$, which are given in Table 1 .

\section{Conclusion}

The paper presents a technique for preparing a graphene aerogel used as an effective sorption material for removing a synthetic organic dye $\mathrm{MB}$ from an aqueous solution. The physicochemical properties of the sorbent were investigated - surface morphology (scanning electron microscopy), the thermal stability of the material and the ordering of the graphene structure were determined. The maximum adsorption capacity of graphene aerogel was determined $-420 \mathrm{mg} / \mathrm{g}$, as well as the reference material - coconut AC - $205 \mathrm{mg} / \mathrm{g}$. The time for the onset of the adsorption equilibrium of the process with the use of graphene aerogel was found to be $7 \mathrm{~min}$.

Also, the experimental kinetic data were described using the well-known equations of kinetic models (pseudo-first and pseudo-second order, Elovich and intraparticle diffusion). As a result, it was revealed that the experimental dependences have high correlation coefficients $R^{2}$ with the calculated values obtained using the pseudo-second order model, which allows us to assert the predominant effect of the chemical sorption of the MB dye on the graphene aerogel, as well as coconut AC. The good convergence of the results from the internal diffusion model with the experimental data indicates a significant contribution to the overall adsorption rate of the penetration of dye molecules into the pores of the sorbents.

Thus, it has been established that a new material, graphene aerogel, is a promising sorbent in the processes of removing organic molecules from aqueous solutions.

\section{References}

1. Aung W.M., Marchenko M.V., Troshkina I.D., Burakova I.V., Gutnik I.V., Burakov A.E., Tkachev A.G. Scandium Adsorption from Sulfuric-Chloride Solutions by Nanocomposite PANI/CNTs. Advanced materials and technologies, 2019, 4(16), 58-65. doi: 10.17277/ amt.2019.04.058-065

2. Ali I., Burakov A.E., Melezhik A.V., Babkin A.V., Burakova I.V., Neskoromnaya E.A., Galunin E.V., Tkachev A.G., Kuznetsov D.V. Removal of Copper(II) and Zinc(II) Ions in Water on a Newly Synthesized Polyhydroquinone/Graphene Nanocomposite Material:
Kinetics, Thermodynamics and Mechanism. Chemistry Select, 2019, 4, 43, 12708-12718. doi: 10.1002/slct. 201902657

3. Burhan A., Suleyman K., Ahmet U., Canbolat G., Vijay K.T. Chemistry, Structures, and Advanced Applications of Nanocomposites from Biorenewable Resources. Chemical Reviews, 2020, 120(17), 93049362. doi: 10.1021/acs.chemrev.9b00553

4. Goncharov A.I., Kornilov M.Yu. Spravochnik po khimii [Chemistry Handbook], Ed. 2. Kiev, izdatel'skoye ob"yedineniye «Vishcha shkola», 1978, 308 p. (Rus)

5. Mahmoud M.E., Nabil G.M., Khalifa M.A., El-Mallah N.M., Hassouba H.M. Effective removal of crystal violet and methylene blue dyes from water by surface functionalized zirconium silicate nanocomposite. Journal of Environmental Chemical Engineering, 2019, 7(2), 103009. doi: 10.1016/j.jece. 2019.103009

6. Dao T.M., Le Luu T. [Synthesis of activated carbon from macadamia nutshells activated by $\mathrm{H}_{2} \mathrm{SO}_{4}$ and $\mathrm{K}_{2} \mathrm{CO}_{3}$ for methylene blue removal in water]. Bioresource Technology Reports, 2020, 12, 100583. doi: 10.1016/j.molstruc.2020.128323

7. Wu Z., Huang W., Shan X., Li Z. [Preparation of a porous graphene oxide/alkali lignin aerogel composite and its adsorption properties for methylene blue]. International Journal of Biological Macromolecules, 2020, 143, 325-333. doi: 10.1016/ j.ijbiomac.2019.12.017

8. Yao X., Ji L., Guo J., Ge S., Lu W., Cai L., Wang Y., Song W., Zhang H. [Magnetic activated biochar nanocomposites derived from wakame and its application in methylene blue adsorption]. Bioresource Technology, 2020, 302, 122842. doi: 10.1016/ j.biortech.2020.122842

9. Syutova A.I., Alibekov S.Ya., Maryashev A.V., Salmanov R.S., Syutov N.P. Tekhnologiya ochistki stochnykh vod $\mathrm{S}$ primeneniyem voloknistykh materialov [Wastewater treatment technology using fibrous materials], Zhurnal Vestnik Kazanskogo tekhnologicheskogo universiteta, 2016, 183-185. (Rus)

10. El-Mekkawi D.M., Ibrahim F.A., Selim M.M. Removal of methylene blue from water using zeolites prepared from Egyptian kaolins collected from different sources. Journal of Environmental Chemical Engineering, 2016, 4, 1417-1422. doi: 10.1016/ j.jece.2016.01.007

11. Xu H., Zhang P., Zhou S.-Y., Jia Q. Fullerene Functionalized Magnetic Molecularly Imprinted Polymer: Synthesis, Characterization and Application for Efficient Adsorption of Methylene Blue. Chinese Journal of Analytical Chemistry, 2020, 48, e20107e20113. doi: 10.1016/S1872-2040(20)60045-7 
12. Kaya I., Yagmur H.K. Synthesis and characterization of poly(3,5-diaminobenzoic acid) via enzymatic and oxidative polymerization and application in methylene blue adsorption. Journal of Molecular Structure, 2020, 128323.

13. Mpatani F.M., Aryee A.A., Kani A.N., Guo Q., Dovi E., Qu L., Li Z., Han R. Uptake of micropollutant-bisphenol A, methylene blue and neutral red onto a novel bagasse- $\beta$-cyclodextrin polymer by adsorption process. Chemosphere, 2020, 259, 127439. doi: 10.1016/j.chemosphere.2020.127439

14. Alp Arici T., Yesilel O.Z., Arici M., TW J. A water-stable $2 \mathrm{D}+2 \mathrm{D} \rightarrow 3 \mathrm{D}$ polycatenated coordination polymer for selective adsorption of methylene blue and detection of $\mathrm{Fe}^{3+}$ ion from aqueous solution. Journal of the Taiwan Institute of Chemical Engineers, 2020, 114, 300-310.

15. Bayat M., Javanbakht V., Esmaili J. Synthesis of zeolite/nickel ferrite/sodium alginate bionanocomposite via a co-precipitation technique for efficient removal of water-soluble methylene blue dye. International Journal of Biological Macromolecules, 2018, 116, 607-619. doi: 10.1016/j.ijbiomac.2018.05.012.

16. Ahmed M.J., Okoye P.U., Hummadi E.H., Hameed B.H. High-performance porous biochar from the pyrolysis of natural and renewable seaweed (Gelidiella acerosa) and its application for the adsorption of methylene blue. Bioresource Technology, 2019, 278, 159-164. doi: 10.1016/j.biortech.2019.01.054

17. Wang B., Gao B., Zimmerman A.R., Lee X. Impregnation of multiwall carbon nanotubes in alginate beads dramatically enhances their adsorptive ability to aqueous methylene blue. Chemical Engineering Research and Design, 2018, 133, 235-242. doi: 10.1016/j.cherd.2018.03.026

18. Eltaweil A.S., Elgarhy G.S., El-Subruiti G.M., Omer A.M. Carboxymethyl cellulose/carboxylated graphene oxide composite microbeads for efficient adsorption of cationic methylene blue dye. International Journal of Biological Macromolecules, 2020, 154, 307-318. doi: 10.1016/j.ijbiomac.2020.03.122

19. Danks A.E., Hall S.R., Schnepp Z. The evolution of 'sol-gel' chemistry as a technique for materials synthesis. Materials Horizons, 2016, 3(2), 91-112. doi: 10.1039/C5MH00260E

20. Feinle A., Elsaesser M.S., Huesing N. Sol-gel synthesis of monolithic materials with hierarchical porosity. Chemical Society Reviews, 2016, 45(12), 3377-3399. doi: 10.1039/C5CS00710K

21. Suh D. J., Park T.-J. Sol-Gel Strategies for Pore Size Control of High-Surface-Area TransitionMetal Oxide Aerogels. Chemistry of Materials, 1996, 8(2), 509-513. doi: 10.1021/cm950407g

22. Bo Z., Shuai X., Mao S., Yang H., Qian J., Chen J., Yan J. Green preparation of reduced graphene oxide for sensing and energy storage applications. Scientific Reports, 2014, 4(1), 4684. doi: 10.1038/ srep04684

23. De Silva K.K.H., Huang H.-H., Joshi R.K., Yoshimura M. [Chemical reduction of graphene oxide using green reductants] Carbon, 2017, 119, 190-199. doi: 10.1016/j.carbon.2017.04.025

24. Zhu X., Liu Q., Zhu X., Li C., Xu M., Liang Y. Reduction of Graphene Oxide Via Ascorbic Acid and Its Application for Simultaneous Detection of Dopamine and Ascorbic Acid. International Journal of Electrochemistry, 2012, 7, 5172-5184.

25. Neskoromnaya E.A., Burakov A.E., Melezhik A.V., Babkin A.V., Burakova I.V., Kurnosov D.A., Tkachev A.G. Synthesis and Evaluation of Adsorption Properties of Reduced Graphene Oxide Hydro- and Aerogels Modified by Iron Oxide Nanoparticles. Inorganic Materials: Applied Research, 2020, 11(2), 467-475.

26. Buslaeva E.Yu. Sverkhkriticheskiy izopropanol kak reagent $\mathrm{v}$ organicheskoy, metalloorganicheskoy, neorganicheskoy khimii i nanotekhnologii [Supercritical isopropanol as a reagent in organic, organometallic, inorganic chemistry and nanotechnology], RENSIT, 2012, 4(2), 38-49. (Rus)

27. Ho Y.S., McKay G.A Comparison of Chemisorption Kinetic Models Applied to Pollutant Removal on Various Sorbents. Process Safety and Environmental Protection, 1998, 76(4), 332-340. doi: $10.1205 / 095758298529696$ 